\title{
ANALISIS PRODUKTIVITAS TENAGA KERJA DI AREA PELABUHAN (STUDI PADA PT. ASDP WILAYAH KERJA KAYANGAN LOMBOK TIMUR)
}

\author{
RENDI ARI PURWANTO1), I GEDE PUTU WARKA ${ }^{2)}$, ISYA ASHARI ${ }^{3)}$ \\ 1) Alumni Jurusan Teknik Sipil Fakultas Teknik Universitas Mataram \\ ${ }^{2,3)}$ Jurusan Teknik Sipil Fakultas Teknik Universitas Mataram
}

e-mail : igedeputuwarka@gmail.com

\begin{abstract}
ABSTRAK
Penelitian ini bertujuan untuk mengetahui pengaruh umur, pengalaman kerja, keahlian pekerja, kesehatan pekerja, kesesuaian upah, kondisi lapangan dan alat bantu terhadap tingkat produktivitas tenaga kerja pada usaha pelabuhan kayangan dan KMP Dingkis khususnya pada cleaning service dan kepil. Analisis data pada penelitian ini menggunakan bantuan Software SPSS. Dalam penelitian ini dilakukan analisis regresi linier berganda untuk mengetahui arah hubungan antara variabel independen dengan variabel dependen apakah masing-masing variabel independen berhubungan positif atau negatif dan untuk memprediksi nilai dari variabel dependen apabila nilai variabel independen mengalami kenaikan atau penurunan. Data yang digunakan berskala interval atau rasio.

Dari hasil analisis yang telah dilakukan besarnya tingkat produktivitas pekerja pada pekerjaan cleaning service dan kepil pada PT. ASDP Wilayah Kerja Kayangan Lombok Timur sebesar 85,53\%, artinya tingkat produktivitasnya sangat baik. Secara simultan umur,pengalaman, keahlian. kesehatan, kesesuaian upah, kondisi lapangan dan sarana bantu berpengaruh nyata terhadap produktivitas tenaga kerja, dengan $F$ test $(10,568)>\mathrm{F}$ tabel $(2,148)$. Secara varsial yang dominan mempengaruhi produktivitas tenaga kerja adalah : upah tenaga kerja,Sarana bantu, Kesehatan dan pengalaman tenaga kerja. Hal ini dapat dilihat dari $\mathrm{T}$ hitung $>\mathrm{T}$ tabel, sedangkan umur, keahlian dan kondisi lapangan berpengaruh terhadap produktivitasm namun tidak nyata, karena $\mathrm{T}$ hitung $<\mathrm{T}$ tabel. Secara simultan semua variabel berpengaruh signifikan karena memiliki nilai $\mathrm{R}$ atau korelasi yang tinggi sebesar 0,722. Variabel yang paling dominan berpengaruh terhadap produktivitas tenaga kerja adalah kesesuaian upah.
\end{abstract}

Kata kunci : produktivitas,tenaga kerja,faktor produktivitas.

\section{ABSTRACT}

This study aims to determine the effect of age, work experience, expertise of workers, health of workers, suitability of wages, field conditions and tools on the level of labor productivity in Kayangan port business and KMP Dingkis especially in cleaning services and kepil. Data analysis in this study uses the help of SPSS Software. In this study multiple linear regression analysis was conducted to determine the direction of the relationship between the independent variable and the dependent variable whether each independent variable is positively or negatively related and to predict the value of the dependent variable if the value of the independent variable increases or decreases. Data used is interval or ratio scale.

From the results of the analysis that has been carried out the level of productivity of workers in the cleaning service and kepil work at PT. ASDP East Lombok Kayangan Work Area is 85.53\%, meaning that the productivity level is very good. Simultaneously age, experience, expertise. health, wage suitability, field conditions and supporting facilities have a significant effect on labor productivity, with $F$ test $(10,568)>F$ table $(2,148)$. The partial dominant influence on labor productivity is: labor wages, supporting facilities, health and labor experience. This can be seen from $T$ count $>T$ table, while age, expertise and field conditions affect productivity but not real, because $T$ count $<T$ table. Simultaneously all variables have a significant effect because they have an $R$ value or a high correlation of 0.722 . The most dominant variable influencing labor productivity is wage suitability.

Keywords: productivity, labor, productivity factors. 


\section{PENDAHULUAN}

\section{Latar Belakang}

Operasional pelabuhan adalah suatu rangkaian kegiatan yang dikerjakan dalam waktu terbatas menggunakan sumber daya tertentu dengan harapan untuk memperoleh hasil yang terbaik pada waktu yang akan datang. Sumber daya merupakan faktor penentudalam keberhasilan suatu pelabuhan. Sumber daya yang berpengaruh dalam operasional pelabuhan terdiri dari man, materials, machine, money dan method.

Sumber daya manusia adalah salah satu faktor yang sangat berpengaruh dalam sebuah pekerjaan, termasuk dalam operasional pelabuhan. Produktivitas tenaga kerja yang baik sangat diperlukan untuk keberhasilan operasional pelabuhan. Produktivitas tenaga kerja akan sangat berpengaruh juga terhadap besarnya keuntungan atau kerugian operasional pelabuhan.

Dalam pelaksanaan dilapangan hal tersebut terkadang bisa terjadi dikarenakan tenaga kerja yang kurang efektif di dalam pekerjaannya. Selain kegiatan-kegiatan yang kurang efektif di atas yang menyebabkan hambatan produktivitas, masih ada faktor lain yang menjadi pengaruh dalam produktivitas tenaga kerja antara lain kondisi lapangan dan sarana bantu, keahlian pekerja, faktor umur atau usia pekerja, kesesuaian upah, pengalaman dalam bekerja, kesehatan pekerja, koordinasi dan perencanaan, jenis kontrak kerja, manajerial atau manajemen lapangan.

Variabel-variabel tersebut adalah hal yang tentu menjadi variabel yang berpengaruh terhadap produktivitas tenaga kerja. Oleh karena itu dalam usaha menganalisa produktivitas tenaga kerja harus dipertimbangkan variabel-variabel yang mungkin dapat berpengaruh terhadap tingkat produktivitasnya.

\section{Tujuan dan Kegunaan Penelitian}

Penelitian ini bertujuan untuk mengetahui 1. Apakah ada pengaruh secara simultan antara umur, pengalaman kerja, keahlian, kesehatan pekerja, kesesuaian upah, kondisi lapanan dan alat bantu) terhadap produktivitas tenaga kerja, 2). Diantara variable umur, pengalaman kerja, keahlian, kesehatan pekerja, kesesuaian upah, kondisi lapanan dan alat bantu, variable yang manakah secara parsial dominan berpengaruh terhadap produktivitas tenaga kerja.

Penelitian ini diharapkan dapat digunakan sebagai bahan pertimbangan bagi pengambil kebijakan, yang berkaitan dengan produktivitas tenaga kerja.

\section{METODE PENELITIAN}

\section{Jenis Penelitian}

Penelitian ini merupakan penelitian deskriptif yaitu penelitian dengan mendeskripsikan atau mengintepretasikan data - data yang sudah dihasilkan, kemudian disimpulkan secara kualitatif atau dengan narasi-narasi atau dalam kata - kata.

\section{Tempat Penelitian}

Penelitian ini dilaksanakan di pelabuhan Kayangan di KMP Dengkis khususnya pada cleaning service, kepil dan usaha pelabuhan

\section{Pengukuran Produktivitas Tenaga Kerja}

Dalam penelitian ini variabel yang mempengaruhi produktivitas kerja yang diukur adalah: 1). Umur tenaga kerja 2). Pengalaman kerja, 3). Keahlian kerja, 4).Kesehatan Kerja, 5 ). Kesesuaian upah, 6). Kondisi Lapangan 7). Alat bantu

Dari variable produktivitas yang diukur, peneliti mengajukan pertanyaan dengan : Sangat sering, Sering, Kadang-kadang, Tidak pernah. Dari pertanyaan-pertanyaan tersebut diberikan skor dengan mengunakan skala likert 4,3,2,1 untuk yang bernilai positif, sedangkan yang bernilai negative sebaliknya ( Hasbi, N, 2015) 


\section{Analisis Data}

1. Data-data yang terkumpul dianalisis dengan tabel frekwensi, sedangkan data lanjutan dianalisis dengan Regresi Linear berganda (Hasby, N,2015). $Y=\mathrm{Y}^{\prime}=\mathrm{a}+\mathrm{b} 1 \mathrm{X} 1+\mathrm{b} 2 \mathrm{X} 2+\ldots . .+\mathrm{bnXn}$

2. Untuk mengetahui pengaruh secara simultan digunakan Uji $\mathrm{F}$, sedangkan untuk mengatahui pengaruh secara parsial digunakan uji $\mathrm{T}$

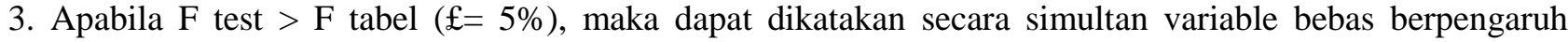
terhadap variable terikat

4. Apabila $\mathrm{T}$ test $>\mathrm{T}$ tabel $(£=5 \%)$, maka secara parsial variable bebas berpengarub terhadap variable terikat

5. Uji Koefisien Determinasi $\left(\mathrm{R}^{2}\right)$, untuk mengetahui persentase sumbangan pengaruh variabel independen $(\mathrm{X} 1, \mathrm{X} 2, \ldots \ldots \mathrm{Xn})$ secara serentak terhadap variabel dependen $(\mathrm{Y})$. Koefisien ini menunjukkan seberapa besar prosentase variasi variabel independen yang digunakan dalam model mampu menjelaskan variasi variabel dependen. R2 sama dengan 0 , maka tidak ada sedikitpun prosentase sumbangan pengaruh yang diberikan variabel independen terhadap variabel dependen, atau variasi variabel independen yang digunakan dalam model tidak menjelaskan sedikitpun variasi variabel dependen. Sebaliknya R2 sama dengan 1, maka prosentase sumbangan pengaruh yang diberikan variabel independen terhadap variabel dependen adalah sempurna, atau variasi variabel independen yang digunakan dalam model menjelaskan $100 \%$ variasi variabel dependen.

\section{HASIL DAN PEMBAHASAN}

\section{Analisis Data Deskriptif}

Berdasarkan hasil penelitian yang telah dilakukan terhadap 76 tenaga kerja di pelabuhan Kayangan, Lombok Timur, diperoleh gambaran mengenai umur, tingkat pengalaman, keahlian, kesehatan, kesesuaian upah, kondisi lapangan dan sarana bantu sebagai berikut:

Tabel 1: Jumlah Responden Berdasarkan atas umur,pengalaman, keahlian. kesehatan, kesesuaian upah, kondisi lapangan dan sarana bantu

\begin{tabular}{|l|l|c|}
\hline \multicolumn{1}{|c|}{ Urian } & \multicolumn{1}{|c|}{ Klasifikasi } & Jumlah \\
\hline \multirow{4}{*}{ Umur } & $<20$ tahun & $0(0,00)$ \\
\cline { 2 - 3 } & $20-30$ tahun & $11(14,46)$ \\
\cline { 2 - 3 } & $31-40$ tahun & $29(38,16)$ \\
\cline { 2 - 3 } & $>40$ tahun & $36(47,37)$ \\
\cline { 2 - 3 } & Jumlah & $76(100)$ \\
\hline Pengalaman & $<1$ tahun & $3(3,95)$ \\
\cline { 2 - 3 } & $1-2$ tahun & $11(14,47)$ \\
\cline { 2 - 3 } & $3-4$ tahun & $10(13,16)$ \\
\cline { 2 - 3 } & $>4$ tahun & $52(68,42)$ \\
\cline { 2 - 3 } & Jumlah & $76(100)$ \\
\hline Pelatihan Keahlian & Tidak pernah & $43(56,58)$ \\
\cline { 2 - 3 } & 1 kali & $15(19,74)$ \\
\cline { 2 - 3 } & 2 kali & $13(17,11)$ \\
\cline { 2 - 3 } & $>2$ kali & $5(5,58)$ \\
\cline { 2 - 3 } & Jumlah & $76(100)$ \\
\hline & Tidak kerja & $11(14,47)$ \\
\cline { 2 - 3 } & karena sakit & $28(36,84)$ \\
\cline { 2 - 3 } & Tidak pernah & $32(42,11)$ \\
\cline { 2 - 3 } & 1 kali & $76(100)$ \\
\cline { 2 - 3 } & 2 kali & $5(6,58)$ \\
\cline { 2 - 3 } & $>2$ kali & \\
\cline { 2 - 3 } & Jumlah & \\
\hline
\end{tabular}

Lanjutan Tabel 1

\begin{tabular}{|l|l|c|}
\hline \multicolumn{1}{|c|}{ Urian } & \multicolumn{1}{|c|}{ Klasifikasi } & Jumlah \\
\hline Kesesuaian upah & Tidak Setuju & $11(14,47)$ \\
\cline { 2 - 3 } & Kurang Setuju & $27(35,53)$ \\
\cline { 2 - 3 } & Setuju & $20(26,32)$ \\
\cline { 2 - 3 } & Sangat Setuju & $18(23,68)$ \\
\cline { 2 - 3 } Mendisi lapangan & & $76(100)$ \\
\cline { 2 - 3 } & Tidak Setuju & $22(28,95)$ \\
\cline { 2 - 3 } & Kurang Setuju & $33(43,42)$ \\
\cline { 2 - 3 } & Setuju & $6(7,89)$ \\
\cline { 2 - 3 } & Sangat Setuju & $15(19,74)$ \\
\cline { 2 - 3 } & & $76(100)$ \\
\hline Sarana bantu & Tidak Setuju & $3(3,95)$ \\
\cline { 2 - 3 } & Kurang Setuju & $8(10,53)$ \\
\cline { 2 - 3 } & Setuju & $39(51,32)$ \\
\cline { 2 - 3 } & Sangat Setuju & $26(34,21)$ \\
\cline { 2 - 3 } & & $76(100)$ \\
\hline
\end{tabular}

Sumber : Data Primer Diolah

Keterangan : Angka dalam kurung adalah prosentase 


\section{Analisis Data Deskriptif Produktivitas Pekerja (Variabel Y)}

Tabel 2. Distribusi jawaban responden mengenai variabel produktivitas kerja (Y)

\begin{tabular}{|c|c|c|c|c|c|c|c|c|c|c|}
\hline \multirow[t]{2}{*}{ Item } & \multicolumn{2}{|l|}{ SS } & \multicolumn{2}{|l|}{$\mathrm{S}$} & \multicolumn{2}{|c|}{ KD } & \multicolumn{2}{|c|}{$\mathrm{TP}$} & \multicolumn{2}{|c|}{ Total } \\
\hline & $\mathrm{F}$ & $\%$ & $F$ & $\%$ & $\mathrm{~F}$ & $\%$ & $\mathrm{~F}$ & $\%$ & & \\
\hline 1 & 48 & $63 \%$ & 20 & $26 \%$ & 8 & $11 \%$ & 0 & $0 \%$ & 76 & $100 \%$ \\
\hline 2 & 44 & $58 \%$ & 26 & $34 \%$ & 5 & $7 \%$ & 1 & $1 \%$ & 76 & $100 \%$ \\
\hline 3 & 34 & $45 \%$ & 37 & $49 \%$ & 4 & $5 \%$ & 1 & $1 \%$ & 76 & $100 \%$ \\
\hline 4 & 36 & $47 \%$ & 30 & $40 \%$ & 9 & $12 \%$ & 1 & $1 \%$ & 76 & $100 \%$ \\
\hline 5 & 40 & $53 \%$ & 27 & $35 \%$ & 8 & $11 \%$ & 1 & $1 \%$ & 76 & $100 \%$ \\
\hline
\end{tabular}

Sumber : Data Primer Diolah

$\begin{array}{rrl}\text { Keterangan: } & \text { SS } & \text { : Sangat Sering } \\ & \mathrm{S} & : \text { Sering } \\ \mathrm{KD} & \text { : Kadang-Kadang } \\ \mathrm{TP} & \text { : Tidak Pernah }\end{array}$

Untuk menghitung skor yang diperoleh seorang pekerja digunakan rumus:

Skor $=\frac{\text { jumlah skor yang diperoleh }}{\text {. }}$

Skor maksimal diperoleh dari: Jumlah item $\mathrm{x}$ nilai terbesar untuk setiap item

Berikut kriteria interpretasi skor berdasarkan interval:

Angka 0\% - 24,99\% = Jelek

Angka 25\% - 49,99\% = Cukup

Angka 50\% - 74,99\% = Baik

Angka 75\% - 100\% = Sangat baik

\section{Analisis Regresi Berganda}

Dari nalisis regresi berganda diperoleh hasil sebagai berikut

Tabel 3. Anova

\begin{tabular}{|c|c|c|c|c|c|c|}
\hline \multicolumn{2}{|c|}{ Model } & Sum of Squares & df & Mean Square & F & Sig. \\
\hline \multirow{4}{*}{1} & Regression & 6.735 & 7 & .962 & 10.568 & $.000^{\mathrm{b}}$ \\
& Residual & 6.191 & 68 & .091 & & \\
& Total & 12.926 & 75 & & & \\
\hline
\end{tabular}

Sumber : Data Primer Diolah

F tabel $(\alpha: 0,05 ;$ df1: $7 ;$ df2: 68$)=2,148$

Tabel 3 menunjukkan nilai $\mathrm{F}$ hitung $=10,568$ sedangkan nilai maka $\mathrm{F}$ hitung $=10,568)>\mathrm{F}$ tabel $=$ 2,148), maka dapat disimpulkan bahwa secara simultan variable : umur,pengalaman, keahlian. kesehatan, kesesuaian upah, kondisi lapangan dan sarana bantu berpengaruh nyata terhadap produktivitas tenaga kerja

Untuk melihat hasil uji pengaruh secara parsial, yang manakah secara dominan paling berngaruh terhadap produktivitas dapat diihat Tabel 4. 
Tabel 4. Coefficients

\begin{tabular}{|c|c|c|c|c|c|c|}
\hline & \multirow[b]{2}{*}{ Model } & \multicolumn{2}{|c|}{$\begin{array}{l}\text { Unstandardized } \\
\text { Coefficients }\end{array}$} & \multirow{2}{*}{$\begin{array}{l}\text { Standardized } \\
\text { Coefficients }\end{array}$} & \multirow[b]{2}{*}{$\mathrm{t}$} & \multirow[b]{2}{*}{ Sig. } \\
\hline & & $\mathrm{B}$ & Std. Error & & & \\
\hline \multirow[t]{8}{*}{1} & (Constant) & 1.637 & .286 & & 5.726 & .000 \\
\hline & Umur & .002 & .004 & .052 & .596 & .553 \\
\hline & Pengalaman & .085 & .041 & .180 & 2.085 & .041 \\
\hline & Keahlian & .013 & .038 & .030 & .337 & .737 \\
\hline & Kesehatan & .119 & .045 & .260 & 2.636 & .010 \\
\hline & Upah & .139 & .041 & .337 & 3.408 & .001 \\
\hline & Kondisi Lapangan & .049 & .035 & .125 & 1.385 & .171 \\
\hline & Sarana Bantu & .170 & .050 & .313 & 3.394 & .001 \\
\hline
\end{tabular}

Sumber : Data Primer Diolah

T tabel $(\alpha / 2: 0,025 ;$ df $(n-k-1)=1,995$

Dari tabel di atas, yang dominan mempengaruhi produktivitas tenaga kerja adalah : upah tenaga kerja, Sarana bantu, Kesehatan dan pengalaman tenaga kerja. Hal ini dapat dilihat dari T hitung > T tabel, sedangkan umur, keahlian dan kondisi lapangan berpengaruh terhadap produktivitas tenaga kerja namun tidak nyata, karena $\mathrm{T}$ hitung $<\mathrm{T}$ tabel

\section{Model Persamaan Regresi}

Berdasarkan tabel di atas maka dapat model persamaan regresi berganda berikut.

$Y=1,637+0,002 X 1+0,085 X 2+0,013 X 3+0,139 X 4+0,119 X 5-0,049 X 6+0,170 X 7$

\section{Koefisien Korelasi $(\mathbf{R})$ dan Determinasi $\left(\mathbf{R}^{2}\right)$}

Tabel 5. Model summary

\begin{tabular}{|l|c|r|r|r|r|r|r|r|r|}
\hline \multirow{2}{*}{ Model } & \multirow{2}{*}{$\mathrm{R}$} & \multirow{2}{*}{$\mathrm{R}$ Square } & $\begin{array}{c}\text { Adjusted R } \\
\text { Square }\end{array}$ & $\begin{array}{c}\text { Std. Error of } \\
\text { the Estimate }\end{array}$ & \multicolumn{5}{|c|}{ Change Statistics } \\
\cline { 5 - 10 } & & & & $\begin{array}{c}\text { R Square } \\
\text { Change }\end{array}$ & F Change & df1 & df2 & $\begin{array}{c}\text { Sig. F } \\
\text { Change }\end{array}$ \\
\hline 1 & $.722^{\mathrm{a}}$ & .521 & .472 & .30173 & .521 & 10.568 & 7 & 68 & .000 \\
\hline
\end{tabular}

a. Predictors: (Constant), Sarana Bantu, Kondisi Lapangan, Keahlian, Pengalaman, Umur, Kesehatan, Upah

b. Dependent Variable: Produktivitas Kerja

$\mathrm{R}=0,722$, hubungan simultan antara $\mathrm{X} 1, \mathrm{X} 2, \mathrm{X} 3, \mathrm{X} 4, \mathrm{X} 5, \mathrm{X} 6$ dan X7 dengan $\mathrm{Y}$ adalah sebesar 0,722. Artinya hubungan antara variabel-variabel bebas tersebut dengan $\mathrm{Y}$ berada pada kategori kuat.

$\mathrm{R}^{2}=0,521$, hal ini berarti bahwa variabel $\mathrm{Y}$ dapat dijelaskan/dipengaruhi oleh variabel $\mathrm{X} 1, \mathrm{X} 2, \mathrm{X}$, $\mathrm{X} 4, \mathrm{X} 5, \mathrm{X} 6$ dan X7 sebesar 52,1\%. Sisanya sebesar 46,7\% variabel Y dipengaruhi oleh variabel lain yang tidak dimasukkan dalam penelitian ini 


\section{SIMPULAN DAN SARAN}

\section{Simpulan}

1. Besarnya tingkat produktivitas tenaga kerja pada area pelabuhan PT. ASDP Wilayah Kerja Kayangan Lombok Timur khususnya pada cleaning service, kepil, usaha pelabuhan kayangan dan KMP Dingkis sebesar $85,53 \%$, artinya tingkat produktivitasnya sangat baik.

2. Secara simultan umur,pengalaman, keahlian. kesehatan, kesesuaian upah, kondisi lapangan dan sarana bantu berpengaruh nyata terhadap produktivitas tenaga kerja, dengan $\mathrm{F}$ test $(10,568)>\mathrm{F}$ tabel $(2,148)$

3. Secara varsial yang dominan mempengaruhi produktivitas tenaga kerja adalah : upah tenaga kerja,Sarana bantu, Kesehatan dan pengalaman tenaga kerja. Hal ini dapat dilihat dari $\mathrm{T}$ hitung $>\mathrm{T}$ tabel, sedangkan umur, keahlian dan kondisi lapangan berpengaruh terhadap produktivitasm namun tidak nyata, karena $\mathrm{T}$ hitung $<\mathrm{T}$ tabel

\section{Saran}

Dalam merumuskan kuesioner, sebaiknya pertanyaan harus diujikan kepada responden awal terlebih dahulu untuk mengetahui apakah pertanyaan dapat dijadikan instrumen penelitian.

\section{DAFTAR PUSTAKA}

Anonim.2014, Pedoman Penulisan Tugas Akhir, Universitas Mataram.

Aprilian, T., 2010, Skripsi Analisa Produktivitas Tenaga Kerja Pada Pekerjaan Struktur Rangka Atap Baja, Fakultas Teknik Sipil, Universitas Sebelas Maret Surakarta.

Hasby, Nasrul.,2015, Skripsi Analisa Produktivitas Pekerja Dalam Proyek Jalan (Studi kasus pada proyek pembangunan jalan gerung (patung sapi-mataram). Jurusan Teknik Sipil Fakultas Teknik Universitas Mataram.

Pramesti, G., 2013, Smart Olah Data Penelitian dengan SPSS, Jakarta, Elex Media Komputindo.

Prasetya, Andi \& Koento Dani Wibowo, 2004, Jurnal Analisa Produktivitas Pekerja Dengan Metode Work Sampling, Fakultas Teknik Sipil Universitas Kristen Petra.

Sinungan, M., 2008, Produktivitas Apa Dan Bagaimana. Bumi Aksara. Jakarta

Soeharto, I., 1989, Manajemen Proyek Dari Konseptual Sampai Operasional. Erlangga. Jakarta

Sujianto, A.E., 2009, Aplikasi Statistik dengan SPSS 16.0, PT.Prestasi Pustakarya. Jakarta 